
\title{
$\begin{array}{ll}\text { Research Square } & \begin{array}{l}\text { Preprints are preliminary reports that have not undergone peer review. } \\ \text { They should not be considered conclusive, used to inform clinical practice, } \\ \text { or referenced by the media as validated information. }\end{array}\end{array}$
}

\section{Multiplex real-time RT-PCR method for the diagnosis of SARS-CoV-2 by targeting viral N2, RdRP and human RP genes}

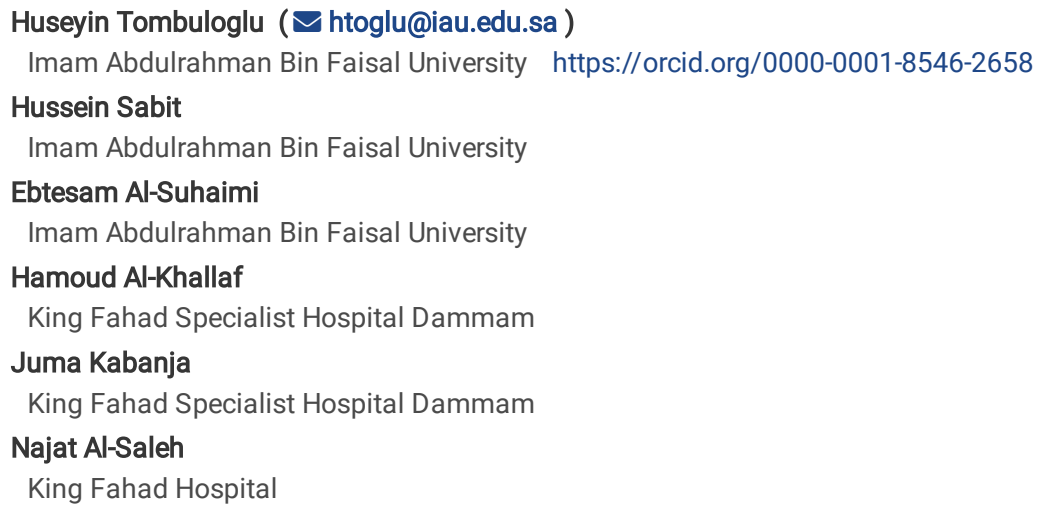

Version of Record: A version of this preprint was published at Scientific Reports on February 18th, 2022. See the published version at https://doi.org/10.1038/s41598-022-06977-z. 


\section{Abstract}

Corona Virus Disease 2019 (COVID-19) is a disease caused by severe acute respiratory syndrome coronavirus 2 (SARS-CoV-2). This pandemic has brought the world to a standstill and threatened human lives. Many methods are known to date to detect this virus. Due to their relative accuracy, polymerase chain reaction (PCR)-based assays are the most frequently applied and considered the gold standard. However, some of these assays have the disadvantages of taking time to show the result and might produce false-negative and false-positive ones. Therefore, designing rapid and accurate PCR-based testing assay is of paramount importance for early detection of this virus and for more efficient control of the spread of this disease. We, here, describe a fast, reliable, easy-touse, and high-throughput multiplex SARS-CoV-2 RT-PCR detection method. The assay was designed to detect two viral genes (N2 and RdRP) and a human gene $(R P)$ simultaneously. The performance and the accuracy of the assay was tested in 28 SARS-CoV-2 positive samples and compared with commercial kits, which showed $100 \%$ positive percent agreement with a limit of detection (LOD) value of 1.25 copies/ $\mu \mathrm{L}$ or 5 copies/reaction. The current assay is found accurate, reliable, simple, sensitive, and specific. It can be used as an optimized SARS-CoV-2 diagnostic assay in hospitals, medical centers, and diagnostic laboratories as well as for research purposes.

\section{Key Messages}

- A multiplex rRT-PCR assay was developed to diagnose SARS-CoV-2.

- The assay targets two viral ( $R d R P$ and $N 2)$ and one human internal control $(R P)$ genes simultaneously.

- The performance of the assay was tested in 28 clinically SARS-CoV-2 positive samples.

- The limit of detection (LOD) of the assay is 1.25 copies/ $\mu \mathrm{L}$ or 5 copies/reaction.

\section{Introduction}

Severe acute respiratory syndrome coronavirus 2 (SARS-CoV-2) belongs to the subfamily Coronavirinae of the family Coronaviridae of the order Nidovirales. Until now (January 2021), about 91 million cases and almost 2 million deaths are related to SARS-CoV-2 (Worldometer 2021;

https://www.worldometers.info/coronavirus). The pandemic that started in late 2019 and continued to increase in 2020 has forced scientists and clinicians to develop new methods for diagnosis and treatment [1]. In addition to some known methods, studies to develop faster, easier, and more reliable methods for SARS-CoV-2 diagnosis continue intensively. The reverse transcription polymerase chain reaction (RT-PCR) is the most common and accepted as the gold standard method for the viral detection [2]. Although RT-PCR is a standard assay, it might produce false-negative and false-positive results [2-4]. Reports showed that patients with negative initial tests became positive after 3-5 repeated swabs [5]. Therefore, the sensitivity and accuracy of this method should be improved. For this purpose, multiplex PCR protocol is proposed that targets multiple genes in the same reaction. By doing so, at least two viral genes are targeted that help to increase the probability to catch the virus especially in the patients having low viral load. In addition, a human housekeeping gene can be added as an internal control to prevent false-negative results that are due to inefficient sampling. Although this method helps to improve the specificity and accuracy, the design of multiplex primers and probe sets is very critical for the PCR efficiency. The formation of self-dimer or hetero-dimer structure reduce the target specificity and may lead to misinterpretation of the results. Therefore, the experimental design as well as the selection of the best primer and probe sets are crucial and needs standardization.

The genome of SARS-CoV-2 contains 14 ORFs encoding for 27 proteins [6]. The surface glycoproteins (S1 and S2) are responsible for binding to the ACE2 (Angiotensin-converting enzyme 2) receptors on the host cell allowing the virus to invade, where S1 bind to the ACE2 receptor and S2 fuses with the host cell membrane [7, 8]. Generally, the genome of this virus is composed of four major structural genes that are translated to spike protein (S), small envelope protein $(E)$, matrix protein $(M)$, and nucleocapsid protein $(\mathrm{N})[6]$, along with some accessory genes. In addition, the genome harbors genes encoding non-structural proteins (Nsp) such as RdRP (Nsp12), the RNA-dependent RNA polymerase enzyme responsible for the replication of the viral genome [9, 10].

RT-PCR tests have been developed to target $R d R P, E, N$, or $S$ genes $[3,11]$. Among these, those targeting $R d R P$ gene were found to be the ones with the highest analytical sensitivity [2]. In addition, the human ribonuclease $\mathrm{P}(R N$ ase $P$ or $R P)$ gene (responsible for the processing of tRNA molecules) is used as an internal control in multiplex RT-PCR protocols recommended by WHO and CDC [12-14]. There is also a need for studies to compare between recently developed assays based on their reproducibility, sensitivity, and accuracy. Therefore, in addition to the experimental design, determining which genes to be targeted by the assay, are also extremely important goals to achieve when designing molecular testing protocols.

The aim of this study is to develop a multiplex real time RT-PCR (rRT-PCR) method for the diagnosis of SARS-CoV-2. The method simultaneously targets viral $N 2, R d R P$ and human $R P$ genes in the same rRT-PCR reaction with a high accuracy and sensitivity.

\section{Materials And Methods}

\section{SARS-CoV-2 genome sequences}

The GISAID (Global Initiative on Sharing All Influenza Data, https://www.gisaid.org]) [20] database was used to retrieve the SARS-CoV-2 genome sequences. At least 100 virus genomes originated from Europe and Asia were selected. In this way, the most sensitive and specific virus targets against possible virus mutations were determined. The sequences were aligned by using the online MUSCLE program (https://www.ebi.ac.uk/Tools/msa/muscle/) with the default setting. The consensus sequences (\%100 alignments) corresponding to the target genes were selected for primer design.

Multiplex primer / probe design 
Programs such as "PrimerPooler", "PrimerPlex" and "Primer3" were used to design multiplex PCR primer and probe sequences that are specific to viral and human gene targets [38]. In the selection of SARS-CoV-2 primers, attention was paid to the selection of genome regions that differ from other SARS-CoV relatives. Therefore, the primers are specific to SARS-CoV-2 virus only and are expected to be free from possible cross reactions with other virus species. Each gene-specific probe was labeled with different fluorescent dye: fluorescein amidides (FAM) for the viral RdRp gene, hexachloro-fluorescein (HEX) for the viral N2 gene, and carboxyrodamine (ROX) for the human RP gene. The concentration, size, and sequence of each primer or probe are indicated in Table 1.

Table 1. The sequence and concentration of primer and probe sets used in PCR reactions.

\begin{tabular}{|c|c|c|c|c|c|}
\hline Primer/probe & Sequence (5-3) & Working Conc. $(\mu \mathrm{M})$ & Final conc. $(\mu \mathrm{M}) *$ & Size (bp) & Reference \\
\hline$R d R p-\mathrm{F}$ & ССTCACTTGTTCTTGCTCGC & 20 & 1 & \multirow{3}{*}{205} & \multirow[t]{3}{*}{ This study } \\
\hline$R d R p-\mathrm{R}$ & GCCGTGACAGCTTGACAAAT & 20 & 1 & & \\
\hline$R d R p$ - Probe & FAM-GTGAAATGGTCATGTGTGGC-BHQ1 & 5 & 0.2 & & \\
\hline$N 2-\mathrm{F}$ & TGAAACTCAAGCCTTACCGC & 20 & 1 & \multirow{3}{*}{160} & \multirow[t]{3}{*}{ This study } \\
\hline$N 2-\mathrm{R}$ & TATAGCCCATCTGCCTTGTG & 20 & 1 & & \\
\hline N2 - Probe & HEX-ATCCATGAGCAGTGCTGAC-BHQ & 5 & 0.2 & & \\
\hline$R P-\mathrm{F}$ & AGATTTGGACCTGCGAGCG & 20 & 1 & \multirow{3}{*}{92} & \multirow{3}{*}{ Universal } \\
\hline$R P-\mathrm{R}$ & GATAGCAACAACTGAATAGCCAAGGT & 20 & 1 & & \\
\hline$R P$ - Probe & ROX-TTCTGACCTGAAGGCTCTGCGCG-BHQ2 & 5 & 0.2 & & \\
\hline
\end{tabular}

* Final concentration represents the concentration of each oligonucleotide in the reaction mixture (20 $\mu \mathrm{l})$.

\section{Sample collection and RNA isolation}

COVID-19 RNA was extracted from nasopharyngeal swab or combined nasopharyngeal/oral swab. Swabs were collected in Virus Liquid Transport MediumVTM per manufacture instruction for collecting and handling (Copan, U.S.A). Specimens were transported to the lab in cool box and kept refrigerated for not more than 8 hours till time of nucleic acid extraction.

Prior to RNA extraction, collection tubes were vortexed; 200 or $400 \mu \mathrm{L}$ of VTM were transferred to 2 mL tubes for RNA extraction using Magna Pure Compact (Roche, Germany) or Elite InGenius ${ }^{\circledR}$ (Elitech, France) systems with elution set to $100 \mu$ l. Finally, $5 \mu \mathrm{L}$ of extracted RNA was used as template for the rRT-PCR.

\section{rRT-PCR conditions}

The following reaction mixture was prepared in a micro-centrifuge tube: $2 \mu \mathrm{L}$ of 10X Buffer, $0.25 \mu \mathrm{L}$ of dNTPs (10 mM each), $0.2 \mu \mathrm{L}$ of uracil-DNA glycosylase (UDG) $(1 \mathrm{U} / \mu \mathrm{L}), 0.25 \mu \mathrm{L}$ of molecular grade dimethyl sulfoxide (DMSO, Sigma-Aldrich), primer and probe mixture, $0.4 \mu \mathrm{L}$ of VitaTaq ${ }^{\circledR} \mathrm{HS}$ polymerase $(2 \mathrm{U} / \mu \mathrm{L})$, $0.5 \mu \mathrm{L}$ of M-MuLV Reverse Transcriptase (200 U/ $\mu \mathrm{L}$ ) (Biolabs, USA), $5 \mu \mathrm{L}$ of RNA template and RNase/DNase-free ddH $\mathrm{H}_{2} \mathrm{O}$ up to $20 \mu \mathrm{L}$.

The reaction mixture was transferred to a 96-well plate (MicroAmp ${ }^{\mathrm{TM}}$ Fast Optical 96-well Reaction Plate $0.1 \mathrm{~mL}$, Applied Biosystems) and sealed with transparent optical film (MicroAmp ${ }^{\text {TM }}$ Optical Adhesive Film, Applied Biosystems). Pseudovira/ RNA containing the viral RdRP and N2 genes and human $R N a s e P(R P)$ mRNA sequences were used as positive control material. In negative control samples, RNase/DNase-free dd $\mathrm{H}_{2} \mathrm{O}$ was added instead of the RNA template.

Applied Biosystems ${ }^{\mathrm{Tm}}$, 7500 Fast Real-Time PCR system was used for rRT-PCR reactions. Prior to this procedure, the instrument was calibrated using the Applied Biosystems ${ }^{\text {TM }} 7500$ Rapid Real Time PCR Systems Spectral Calibration Kit. The following conditions were applied for the rRT-PCR reaction: 1 ) reverse transcription at $42{ }^{\circ} \mathrm{C}$ for 15 minutes, 2) pre-denaturation at $95{ }^{\circ} \mathrm{C}$ for 5 minutes. For the cyclic reactions (x40) 3 ) denaturation at $95{ }^{\circ} \mathrm{C}$ for 5 seconds and 4 ) amplification at $60^{\circ} \mathrm{C}$ for 30 seconds. The reporter dye channel was determined as FAM for the RdRp gene, VIC for the N2 gene, and ROX for the $R N a s e P(R P)$ gene. For the Applied Biosystems ${ }^{\mathrm{TM}}$ real time PCR instrument (7500 and StepOne models), "passive reference" is set to "none".

\section{Amplification efficiency and analytical sensitivity}

The rRT-PCR amplification efficiency (E) was calculated for each viral gene. For this, dilution series of template RNA was prepared and a standard curve was generated. Ct values were drawn for the logarithmic measurement of the template used. Amplification efficiency was calculated according to the following formula:

$E=100 \times\left(10^{-1 / \text { slope }}\right)$

Multiple units are used to display limit-of-detection (LOD), for example viral genomic RNA copies per milliliter of transfer medium (copies/mL), copies/ $\mu \mathrm{L}$, copies per reaction volume, or molarity of the test target, etc, which are sometimes confused [37]. To demonstrate the sensitivity of current assay, the LOD number was calculated and expressed in two different units: 1) the number of copies in one $\mu \mathrm{L}$ of the reaction mixture (copies/ $\mu \mathrm{L})$ and 2$)$ the number of copies in the reaction (copies/reaction). For this, serial dilution of synthetic RNA $\left(5 \times 10^{4}, 5 \times 10^{3}, 5 \times 10^{2}, 5 \times 10^{1}\right.$, and $5 \times 10^{0}$ copies/ $\left.\mu \mathrm{L}\right)$ was prepared. Since $5 \mu \mathrm{L}$ of template solution was used in the PCR reaction, the lowest dilution $\left(5 \times 10^{0}\right.$ copies/ $\left.\mu \mathrm{L}\right)$ contains 25 copies of RNA. In total, 25 copies of RNA in $20 \mu \mathrm{L}$ of reaction mixture correspond to 1.25 copies/ $\mu \mathrm{L}$ or 5 copies/reaction.

\section{Validation of the assay}

To validate the assay (called as mCoV-2), we performed rRT-PCR by using commercially available SARS-CoV-2 detection kits. For this purpose, the same RNA samples $(n=28)$ that were previously extracted from the COVID19 patients were used as the template. The reactions were run using either 
GeneFinder ${ }^{T M}$ COVID-19 Plus RealAmp Kit (GeneFinder, Korea) or RealStar SARS-CoV-2 RT-PCR Kit 1.0 (Altona, Germany).

\section{Data analysis}

The results were evaluated by determining the amplification curve of the target gene and the internal control gene. For the ABI 7500 device, the cycle threshold (Ct or $\mathrm{Cq}$ ) line was automatically adjusted to ensure that the curves are all straight position. For this purpose, ABI 7500 software (v2.3) was used. The positive cut-off value was set at cycle threshold number $\leq 37$ with a sigmoidal curve. Any patient meets the criteria were accepted as positive.

\section{Results}

\section{Standardization of the multiplex rRT-PCR}

A multiplex rRT-PCR assay was optimized for the diagnosis of SARS-CoV-2. The assay simultaneously targets two viral genes (RdRP and N2) and one human gene $(R P)$ as internal control. The assay tested in 28 RNA samples collected from COVID-19 positive individuals. Fig. 1 exhibits the rRT-PCR outputs belonging to COVID-19 positive and negative individuals. In COVID-19 positive specimens, simultaneous amplification of $R P, R d R P$ and $N 2$ genes were obvious (Fig. 1 a). In the COVID-19 negative specimen, the internal control gene $(R P)$ was the only gene amplified with a sigmoidal amplification curve (Fig. 1b). In the positive control reactions, pseudovira/ RNA including N2 and RdRP regions and a human RP mRNA was used as template. The amplification curves were obtained for all targeted genes (Fig. 1c). In the negative control reactions, $\mathrm{ddH}_{2} \mathrm{O}$ was used as the template, which led no amplification line without primer dimer formation (homo-dimer or hetero-dimer). The results showed that the multiplex primer and probe design successfully amplify all targeted genes both in SARS-CoV-2 positive specimen and synthetic positive control samples without forming primer dimer or self-amplification.

In addition, the standard curve analysis was performed to test the accuracy of the assay. For this purpose, a dilution series of clinical RNA was prepared with a dilution factor range of $10^{5}$ to $10^{1}$ (Fig. 2). Triplicate rRT-PCR analysis revealed that the results are consistent across technical replicates. The test ran successfully even on samples diluted $10^{5}$ times. The rRT-PCR efficiency for both $R d R P$ and $N 2$ genes is 99.7 and the $\mathrm{R}^{2}$ value is $>0.997$, which shows the consistency and reliability of the assay.

\section{Validation of the assay}

The validation of the results has been performed by using two different commercially available kits (GeneFinder ${ }^{\mathrm{TM}} \mathrm{COVID}-19$ Plus RealAmp Kit (GeneFinder, Korea) and RealStar SARS-CoV-2 RT-PCR Kit 1.0 (Altona, Germany)) that are targeting different genes such as RdRP, N2, S, and E. Among 28 clinically confirmed SARS-CoV-2 positive samples, the current assay found 25 positives and three negatives. Accordingly, the $\mathrm{Ct}$ value equals and lower than 37 is accepted as positive. Besides, in both assays, the Ct score of those negative samples was higher than 37 , which is out of the CDC and WHO recommendations $[15,16]$. Therefore, the samples having a Ct score of $\geq 37.01$ are accepted as SARS-CoV-2 negative. In this case, the assay exhibited $100 \%$ positive percent agreement with those commercial assays. The distribution of $\mathrm{Ct}$ value obtained from both commercial methods and this mCoV-2 assay are displayed in Fig. 3. Since these kits target different genes, the Ct scores of those genes were combined. Accordingly, it is obvious that the average Ct value of the current assay is lower than those of the genes targeted in the comparative commercial kits. This result demonstrates the high sensitivity of the current assay.

\section{Limit-of-detection (LOD) and rRT-PCR efficiency}

A serial dilution of synthetic RNA $\left(5 \times 10^{4}, 5 \times 10^{3}, 5 \times 10^{2}, 5 \times 10^{1}\right.$, and $5 \times 10^{0}$ copies/ $\left.\mu \mathrm{L}\right)$ was prepared to find out the limit-of-detection (LOD) for $R d R P$ and $N 2$ genes. The amplification plots, the amplification efficiencies $(E)$, and $R^{2}$ score are represented in Fig. 4 . The LOD of $N 2$ gene was $\leq 1.25$ copy/ $\mu \mathrm{L}$ or 5 copy/reaction. Together with, the LOD of $R d R P$ gene was $\leq 1.25$ copy/ $\mu \mathrm{L}$ or 5 copy/reaction. The standard curve analysis revealed that the $\mathrm{E}$ value of $N 2$ and $R d R P$ genes are 100.2 and 99.9 , respectively. The $\mathrm{R}^{2}$ values are 0.9818 for the $N 2$ and 0.9805 for the $R d R P$ gene.

\section{Discussion}

With the emergence of the COVID-19 outbreak, many methods have been developed for the diagnosis of SARS-CoV-2 in the past year. These are mainly divided into nucleic acid-based amplification tests and serological tests. The nucleic acid-based amplification methods, such as rRT-PCR, are based on the amplification of viral RNA [17]. On the other hand, serological tests are based on detecting either the proteins of the COVID-19 virus or human antibodies generated in response to infection such as the immunoglobulin type M (IgM) or immunoglobulin type G (IgG). The most important disadvantage of serological tests is their limited sensitivity to early detection [18]. In general, the development of specific antibodies against the virus begins after the first week, and IgM and IgG production occurs mostly in the second week [19]. Therefore, the sensitivity of serological tests is limited in the acute stage of infection. Another drawback is the possibility of similar antibody responses to the viruses in the same or close families and the possibility of cross-reactivity. This possibility is a serious concern as most human coronaviruses are antigenically close related to each other. Therefore, the WHO and CDC do not recommend the use of pointof-care immunodiagnostic tests for clinical decision-making. Instead, serological tests can be used for research or clinical support purposes [21-23].

Since rRT-PCR method is considered the gold standard in the diagnosis of SARS-CoV-2, WHO and CDC recommend it as the diagnostic test for asymptomatic and mildly symptomatic patients [21, 24]. However, rRT-PCR methods also have some drawbacks such as possible false-negative or false-positive results, the cost, etc [25]. In order to eliminate or minimize those drawbacks, multiplex rRT-PCR methods have been developed that target more than one gene at the same time. By doing this, it is aimed to improve rRT-PCR efficiency and sensitivity. Until now, many studies have been conducted to find the method that can detect the SARS-CoV-2 RNA with the highest sensitivity. For this, different combinations of targeted viral genes were tested in multiplex. According to the WHO recommendations, four viral genes ( $R d R p, E, N$ and $S$ genes) can be used in multiplex rRT-PCR reactions in different combinations [26]. Along with these genes, primer and probe sequences of the human internal / positive control $R N a s e P(R P)$ gene have been published and their use has been recommended by US CDC 
[12]. The studies to improve these protocols are still ongoing. Designing primers with the highest sensitivity towards the target gene, eliminating their cross reactivity, minimizing possible false negative and positive results, optimizing rRT-PCR conditions are examples of what can be improved by those studies. It is worth mention here that recently, Dekker et al. [27] demonstrated a faulty design in $R P$ primer sets defined by the CDC, which is another example of the importance of those improvement studies.

In this study, a multiplex rRT-PCR method has been developed that simultaneously targets the viral N2 and $R d R P$ genes and the human $R P$ gene. The primer and probe sets were designed to obtain the best PCR efficiency and target specificity. The rRT-PCR efficiencies of 10-fold dilutions series of the standards were $>99$ for both N2 and RdRP genes, which matches the criteria for an efficient RT-qPCR assay [28]. Besides, the current protocol allows the diagnosis of SARSCoV-2 RNA with a limit of detection (LOD) value of 1.25 copies/ $\mu \mathrm{L}$ or 5 copies/reaction for both N2 and RdRP genes. The LOD of the CDC's 2019 -nCoV RealTime RT-PCR Diagnostic Panel was found to be $10 \mathrm{copies} / \mu \mathrm{L}$. According to Vogels et al. [29], all SARS-CoV-2 primer and probe sets that has capacity to detect 500 copy/reaction can be used to diagnose SARS-CoV-2. Therefore, the current assay can be said to have a higher sensitivity than recommended and wellknown assays.

The validation of the assay was tested in 28 SARS-CoV-2 positive samples. It is revealed that three samples out of 28 did not match with the results of the commercial kits. In both assays, either commercial or the current one, it is estimated that the Ct score of those negative samples was higher than $>37.01$ which is out of the WHO recommendation [16]. Therefore, in the current mCoV-2 assay, they are called as negative. Accordingly, the Ct value equals and lower than 37 is accepted as positive.

For COVID19, RT-PCR detection kits are commonly destined to amplify the genes $S, E, N, R d R P$, and $O R F 1 a / b$, but $O R F 1 a / b$ and $E$ were mostly applied [30, 31]. In China, Orf $1 a b$ and $N$ genes are regularly used, while $N 1, N 2$ and $N 3$ genes were utilized in US CDC and $E, N$, and RdRP genes in Europe [32]. The importance of $N 1$ and $N 2$ primer-probes is for providing a less conservative but more sensitive than the RdRP-SARSr primer-probes especially in samples that have low viral titers [33,34]. In a recent study, where swabs from confirmed cases were taken from nasopharynx and pharynx targeting ORF1ab and $N$ genes yielded the best sensitivity when compared to positive confirmed samples [34]. Chu et al. [35] have reported two assays that had the capability to achieve a large dynamic range and recommended targeting $N$ gene for screening and the ORF1b gene to confirm the result. The abovementioned studies confirmed the capability of targeting $N$ gene to be utilized in the detection of COVID-19 with other genes. While Li et al. [36] concluded that the more stable $E$ gene is the target for the standardization of coronavirus tests, but $N$ and $R d R P$ genes are mostly targeted to confirm the results. In our study, it seems that targeting $R d R P$ and $N 2$ genes will make the test more sensitive. However, more studies are needed for fast and accurate COVID19 detection.

\section{Conclusion}

Due to the spread of COVID-19 all over the world, there is an urgent need to develop more reliable and sensitive methods and to improve existing methods. Establishing sensitive primers and PCR conditions are extremely important to detect SARS-CoV-2 early and to control the spread of the disease. Current study describes a multiplex rRT-PCR assay that simultaneously targets two viral ( $R d R P$ and $N 2)$ and one human internal control gene ( $R P)$. In addition, the experimental design is free from background (self- or hetero-dimer formations) with high sensitivity. Thanks to this strategy, fast, reliable, and easy-to-use rRTPCR method is obtained to detect SARS-CoV-2. The accuracy of the method should be evaluated in different RT-PCR devices.

\section{Declarations}

Conflict of Interest The authors confirm that the contents of this article have no conflicts of interest.

Funding This study is funded by Institute for Research and Medical Consultations (IRMC) under the project number 2020-IRMC-S-3 and the Deanship of Scientific Research (DSR) of Imam Abdulrahman Bin Faisal University (IAU) Fast track fund of COVID-19 (COVID19-2020-026-IRMC).

Acknowledgment We would like to thank Mr. Geoffrey James T. Moro for technical assistance in conducting RT-PCR experiments. The schema is created with BioRender.com.

Data availability All the authors declare that data and materials are available upon request.

Ethical approval The study is approved by the Institutional Review Board (IRB) at Imam Abdulrahman bin Faisal University (IAU) with an IRB number of IRB2020-13-406.

Consent for publication Not applicable.

Code availability Not applicable.

\section{References}

1. Wiersinga WJ, Rhodes A, Cheng AC, Peacock SJ, Prescott HC (2020) Pathophysiology, transmission, diagnosis, and treatment of coronavirus disease 2019 (COVID-19): a review. Jama 324(8):782-793

2. Corman VM, Landt O, Kaiser M, Molenkamp R, Meijer A, Chu DK et al (2020) Detection of 2019 novel coronavirus (2019-nCoV) by real-time RT-PCR. Euro Surveill 25(3):2000045

3. Chan JFW, Yip CCY, To KKW, Tang THC, Wong SCY, Leung KH et al (2020) Improved molecular diagnosis of COVID-19 by the novel, highly sensitive and specific COVID-19-RdRp/Hel real-time reverse transcription-PCR assay validated in vitro and with clinical specimens. J Clin Microbiol 58(5) 
4. Chen W, Lan Y, Yuan X, Deng X, Li Y, Cai X et al (2020) Detectable 2019-nCoV viral RNA in blood is a strong indicator for the further clinical severity. Emerg Microbes Infect 9(1):469-473

5. Yu F, Yan L, Wang N, Yang S, Wang L, Tang Y et al (2020) Quantitative detection and viral load analysis of SARS-CoV-2 in infected patients. Clin Infect Dis 71(15):793-798

6. Wu A, Peng Y, Huang B, Ding X, Wang X, Niu P et al (2020) Genome composition and divergence of the novel coronavirus (2019-nCoV) originating in China. Cell Host Microbe 27(3):325-328

7. Yang J, Petitjean SJL, Koehler M et al (2020) Molecular interaction and inhibition of SARS-CoV-2 binding to the ACE2 receptor. Nat Commun $11: 4541$

8. Huang Y, Yang C, Xu X et al (2020) Structural and functional properties of SARS-CoV-2 spike protein: potential antivirus drug development for COVID-19. Acta Pharmacol Sin 41:1141-1149

9. Naqvi AAT, Fatima K, Mohammad T, Fatima U, Singh IK, Singh A,et al (2020) Insights into SARS-CoV-2 genome, structure, evolution, pathogenesis and therapies: Structural genomics approach. Biochim Biophys Acta Mol Basis Dis 165878

10. Khan S, Tombuloglu H, Hassanein SE, Rehman S, Bozkurt A, Cevik E et al (2020) Coronavirus diseases 2019: current biological situation and potential therapeutic perspective. Eur J Pharmacol 886:173447

11. Konrad R, Eberle U, Dangel A, Treis B, Berger A, Bengs K et al (2020) Rapid establishment of laboratory diagnostics for the novel coronavirus SARS-CoV-2 in Bavaria, Germany, February 2020. Euro Surveill 25(9):2000173

12. CDC (2020) CDC 2019-Novel Coronavirus (2019-nCoV) Real-Time RT-PCR Diagnostic Panel. https://www.fda.gov/media/134922/download (Accessed: 14 January 2021)

13. Dahdouh E, Lázaro-Perona F, Romero-Gómez MP, Mingorance J, García-Rodriguez J (2020) Ct values from SARS-CoV-2 diagnostic PCR assays should not be used as direct estimates of viral load. J Infect. https://doi.org/10.1016/j.jinf.2020.10.017

14. Zhen W, Berry GJ (2020) Development of a New Multiplex Real-Time RT-PCR Assay for Severe Acute Respiratory Syndrome Coronavirus 2 (SARS-CoV-2) Detection. J Mol Diagn 22(12):1367-1372

15. CDC (2020) FAQs about the CDC DENV-1-4 Real-Time RT-PCR Multiplex Assay. https://www.cdc.gov/dengue/healthcare-providers/testing/moleculartests/faq_rt-pcr.html (Accessed: 14 January 2021)

16. WHO (2020) WHO Emergency Use Assessment Coronavirus disease (COVID-19) IVDs PUBLIC REPORT. October 2020, version 1.0. EUL-0517-204-00. https://extranet.who.int/pqweb/sites/default/files/documents/201005_final_pqpr_eul_0517_204_00_sars_cov2_nucleic_acid_detection\%20\%281\%29.pdf. (Accessed: 24 February 2021)

17. Caruana G, Croxatto A, Coste AT, Opota O, Lamoth F, Jaton K, Greub G (2020) Diagnostic strategies for SARS-CoV-2 infection and interpretation of microbiological results. Clinic Microbiol Infect 26(9):1178-1182

18. Kubina R, Dziedzic A (2020) Molecular and serological tests for COVID-19 a comparative review of SARS-CoV-2 coronavirus laboratory and point-of-care diagnostics. Diagnostics 10(6):434

19. WHO (2020) What we know about the COVID-19 immune response. https://www.who.int/docs/default-source/coronaviruse/risk-comms-updates/update34-immunity-2nd.pdf?sfvrsn=8a488cb6_2 (Accessed: 10 January 2021)

20. The GISAID (Global Initiative on Sharing All Influenza Data, https://www.gisaid.org (Accessed: 05 May 2020)

21. WHO (2020) Laboratory Testing for 2019 Novel Coronavirus (2019-nCoV) in Suspected Human Cases.https://www.who.int/publications-detail/laboratorytesting-for-2019-novel-coronavirus-in-suspected-human-cases-20200117 (Accessed: 10 January 2021)

22. WHO (2020) Advice on the Use of Point-Of-Care Immunodiagnostic Tests for COVID-19. https://www.who.int/news-room/commentaries/detail/advice-onthe-use-of-point-of-care-immunodiagnostic-tests-for-covid-19 (Accessed: 10 January 2021)

23. CDC (2020) Overview of Testing for SARS-CoV-2. https://www.cdc.gov/coronavirus/2019-ncov/hcp/testingoverview.html\#: :text=Authorized\%20assays\%20for\%20viral\%20testing,COVID\%2D19\%2C\%20is\%20present. (Accessed: 14 January 2021)

24. CDC (2020) Testing for COVID-19. https://www.cdc.gov/coronavirus/2019-ncov/symptoms-testing/testing.html (Accessed: 14 January 2021)

25. Shen M, Zhou Y, Ye J, Al-Maskri AAA, Kang Y, Zeng S, Cai S (2020) Recent advances and perspectives of nucleic acid detection for coronavirus. J Pharma Anal 10(2):97-101

26. WHO (2020) Laboratory testing for coronavirus disease 2019 (COVID-19) in suspected human cases: interim guidance, 2 March 2020 (No. WHO/COVID19/laboratory/2020.4). World Health Organization. (Accessed: 10 January 2021)

27. Dekker RJ, Ensink WA, van Leeuwen S, Rauwerda H, Breit TM (2020) Overhauling a faulty control in the CDC-recommended SARS-CoV-2 RT-PCR test. bioRxiv

28. Svec D, Tichopad A, Novosadova V, Pfaffl MW, Kubista M (2015) How good is a PCR efficiency estimate: Recommendations for precise and robust qPCR efficiency assessments. Biomol Detect Quant 3:9-16

29. Vogels CB, Brito AF, Wyllie AL, Fauver JR, Ott IM, Kalinich CC et al (2020) Analytical sensitivity and efficiency comparisons of SARS-CoV-2 RT-qPCR primer-probe sets. Nat Microbiol 5(10):1299-1305

30. Cui F, Zhou HS (2020) Diagnostic methods and potential portable biosensors for coronavirus disease 2019. Biosens Bioelect 112349

31. Sheikhzadeh E, Eissa S, Ismail A, Zourob M (2020) Diagnostic techniques for COVID-19 and new developments. Talanta 121392

32. Bai H, Cai X, Zhang X (2020) Landscape Coronavirus Disease 2019 test (COVID-19 test) in vitro-A comparison of PCR vs Immunoassay vs Crispr-Based test https://doi.org/10.31219/osf.io/6eagn 
33. Lista MJ, Page R, Sertkaya H, Matos P, Ortiz-Zapater E, Maguire TJ et al (2020) Resilient SARS-CoV-2 diagnostics workflows including viral heat inactivation. medRxiv

34. Zhou Y, Pei F, Ji M, Wang L, Zhao H, Li H et al (2020) Sensitivity evaluation of 2019 novel coronavirus (SARS-CoV-2) RT-PCR detection kits and strategy to reduce false negative. PloS One 15(11):e0241469

35. Chu DK, Pan Y, Cheng SM, Hui KP, Krishnan P, Liu Y et al (2020) Molecular diagnosis of a novel coronavirus (2019-nCoV) causing an outbreak of pneumonia. Clin Chem 66(4):549-555

36. Li D, Zhang J, Li J (2020) Primer design for quantitative real-time PCR for the emerging Coronavirus SARS-CoV-2. Theranostics 10(16):7150

37. Arnaout R, Lee RA, Lee GR, Callahan C, Yen CF, Smith KP et al (2020) SARS-CoV2 testing: the limit of detection matters. bioRxiv

38. Brown SS, Chen YW, Wang M, Clipson A, Ochoa E, Du MQ (2017) PrimerPooler: automated primer pooling to prepare library for targeted sequencing. Biol Method Protoc 2(1):bpx006

\section{Figures}

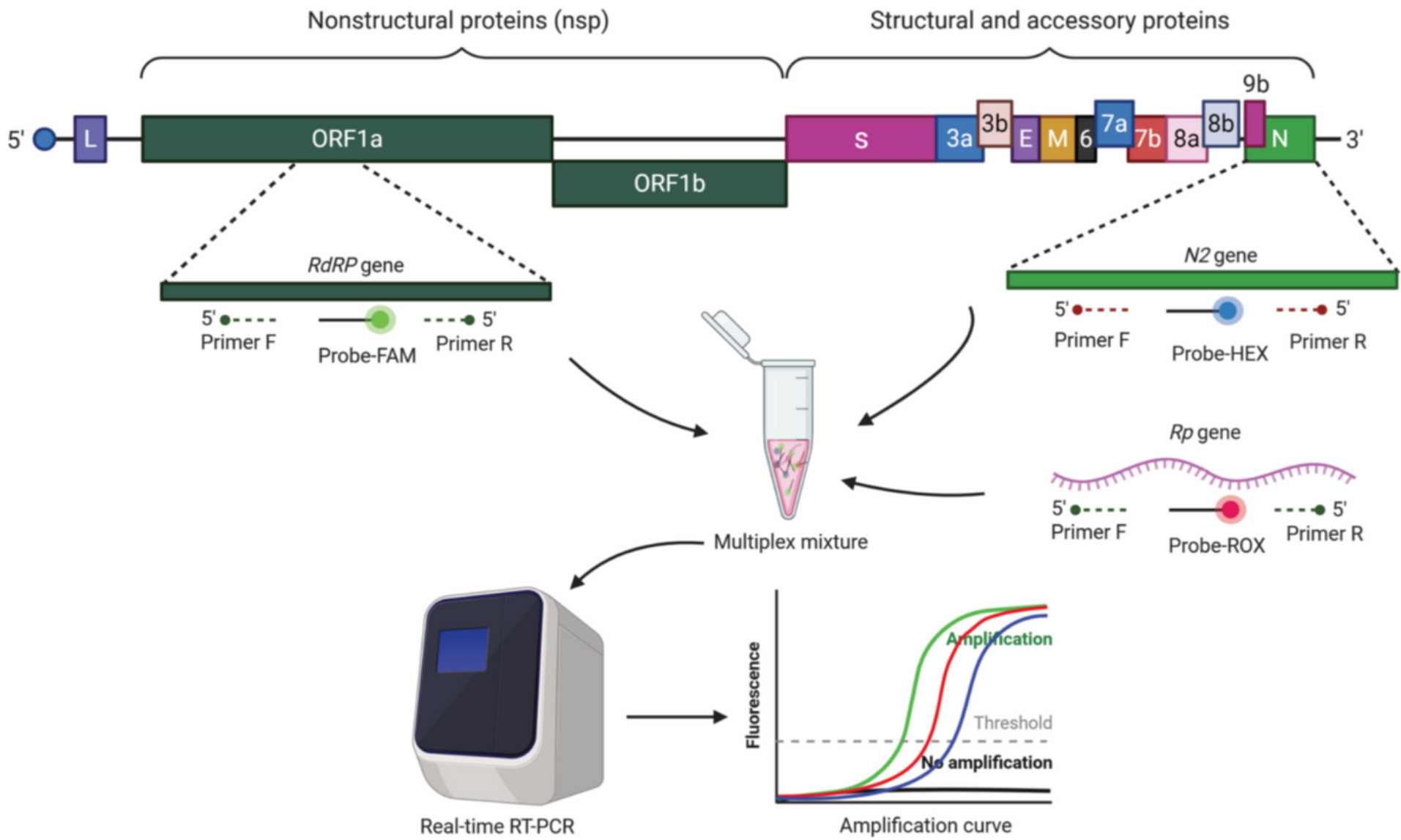

\section{Figure 1}

Schema. Genome structure of SARS-CoV-2 and the targeted genes to be used in multiplex rRT-PCR. 

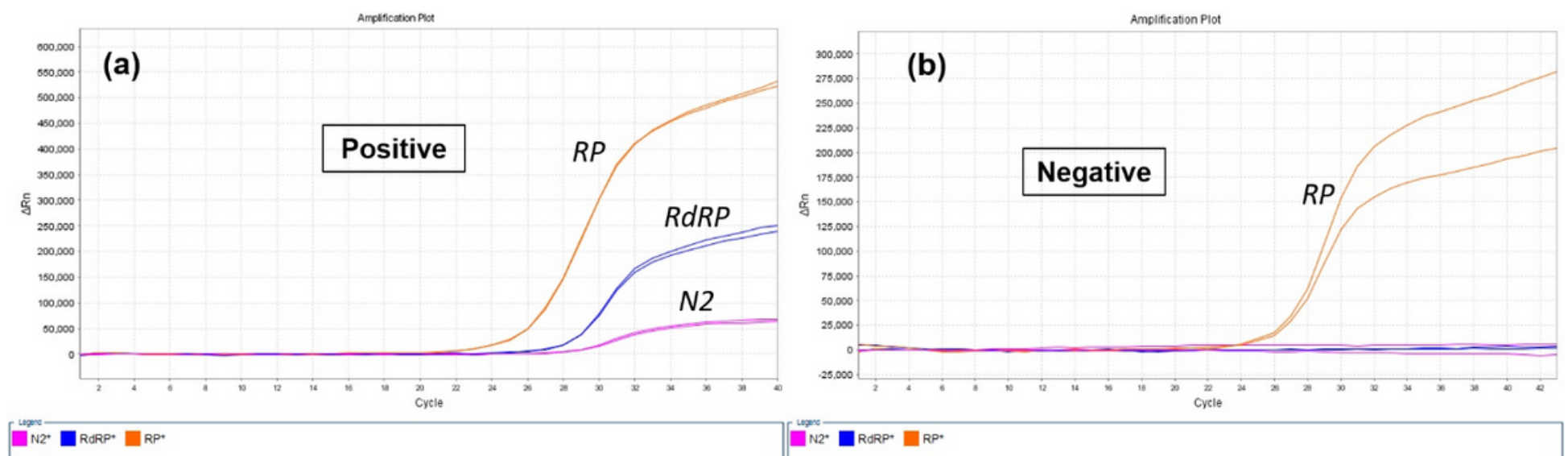

$\mathrm{N}^{*}$ RdRP*
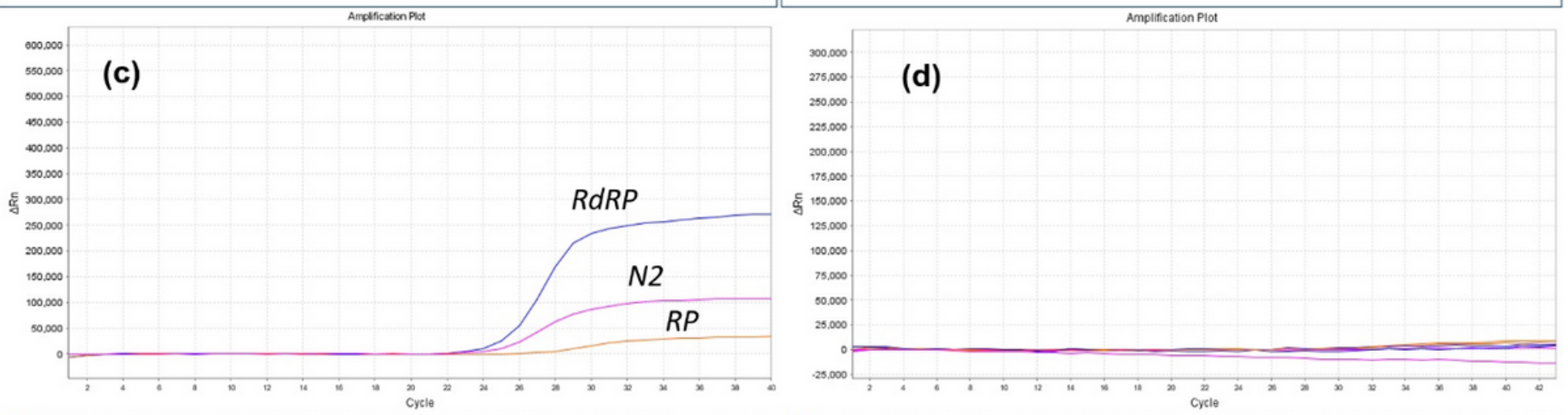

${ }^{2} 2^{*}$ RdRP*

N2* $\mathrm{RdRP*}$ RP*

Figure 2

Amplification curves of clinical samples belongs to (a) SARS-CoV-2 positive and (b) SARS-CoV-2 $\neg$ ative specimens. The amplification curve of (c) positive control and (d) negative control.
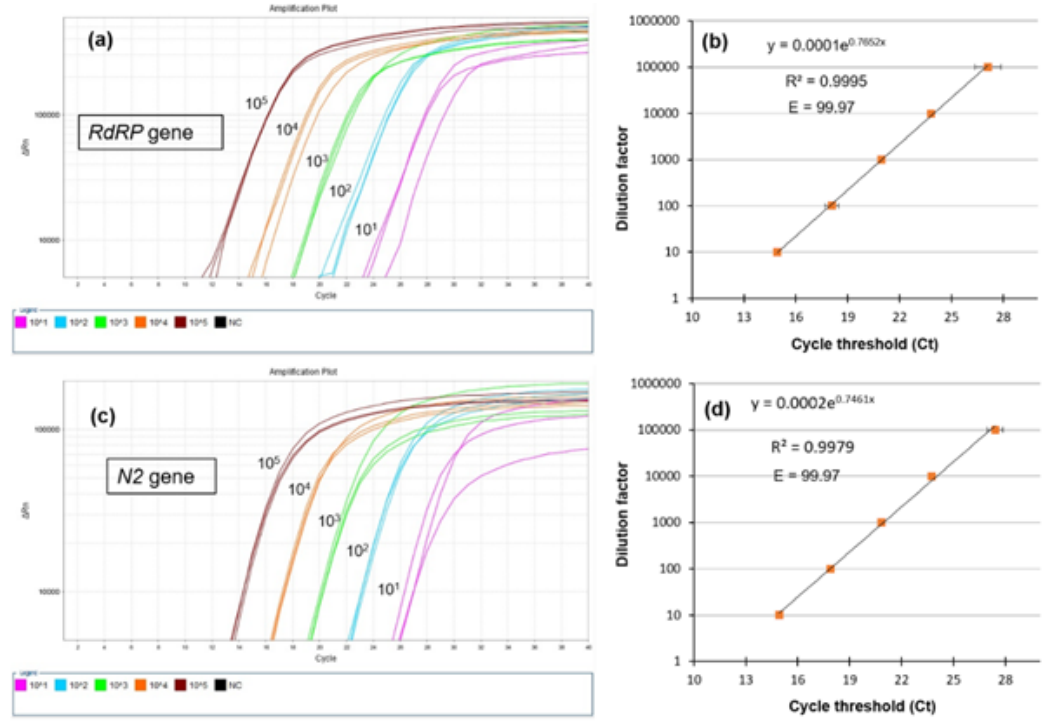

Figure 3

Standard curve analysis for multiplex rRT-PCR of RdRP and N2 primers. The template RNA was serially diluted with a range of 105 to 101 . The reactions were carried out in triplicate. The amplification plots $(a, c)$ and the amplification efficiencies $(E)(b, d)$ were shown on each graph. The error bars represent the standard deviation between the replicates. 


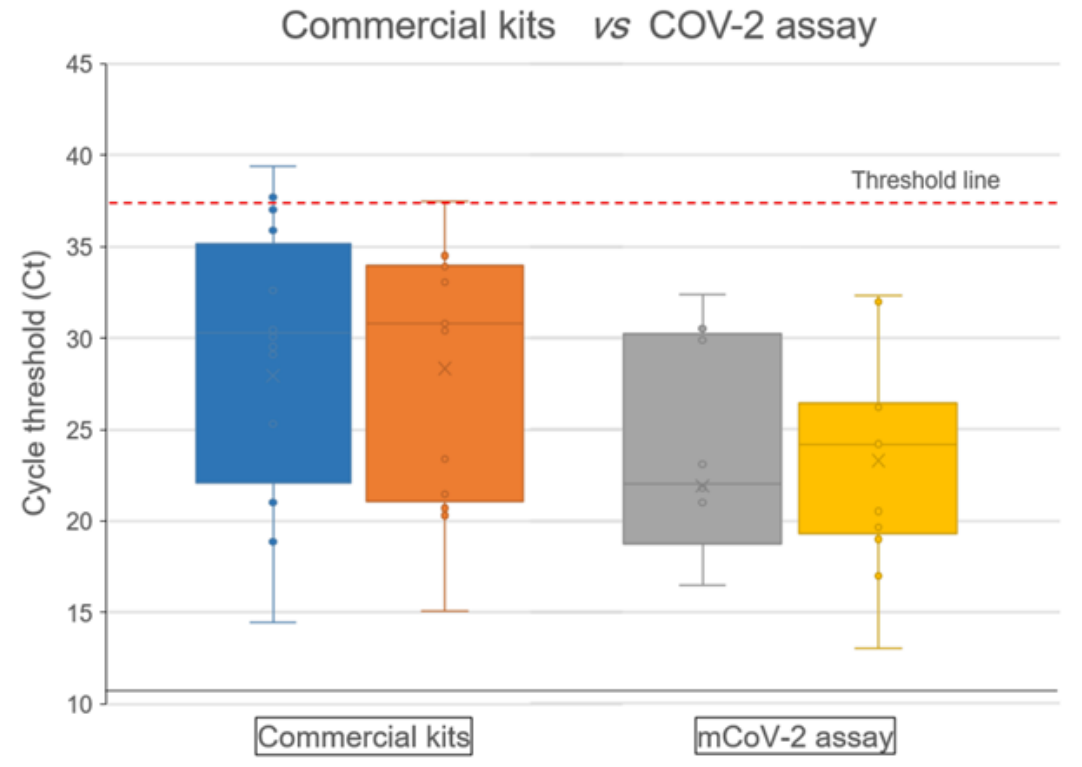

\section{Figure 4}

The cycle threshold (Ct) scores of the same clinical samples tested either the current mCoV-2 assay or commercial kits. Each bar represents different genes, which are RdRP (gray) and N2 (yellow) for mCoV-2 assay; and N2 or S (blue) and RdRP or E (orange) for commercial kits. Dashed line shows the positivity cutoff level equals to Ct 37.
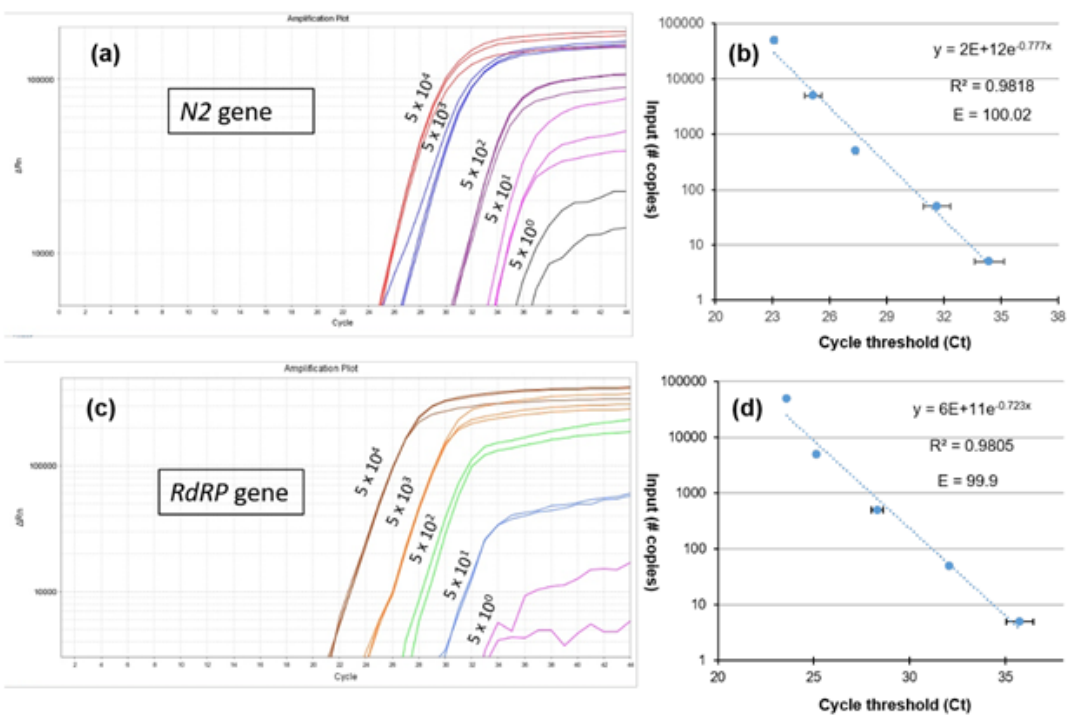

\section{Figure 5}

Determination of the limit of detection (LOD) for RdRP and N2 primers. The $5 \times 104$ copy/ $\mu$ pseudoviral RNA was serially diluted. The amplification plots (a, c) and the amplification efficiencies (E) (b, d) for N2 and RdRP genes were represented, respectively. The R2 value of the trendline and the efficiency (E) of the standard curve were displayed on each graph. The error bars represent the standard deviation between the replicates. 